\title{
Walter Thiel's Embalming Method. Review of Solutions and Applications in Different Fields of Biomedical Research
}

\author{
Método de Embalsamamiento de Walther Thiel. Revisión de las Soluciones \\ y sus Aplicaciones en Diferentes Campos de Investigación Biomédica
}

Nicolás Ernesto Ottone ${ }^{*, * *}$; Claudia A. Vargas ${ }^{* * * * * *}$; Ramón Fuentes ${ }^{*}$ \& Mariano del Sol $^{* * * * * * *}$

OTTONE, N. E.; VARGAS, C. A.; FUENTES, R. \& DEL SOL, M. Walter Thiel's embalming method. Review of solutions and applications in different fields of biomedical research. Int. J. Morphol., 34(4):1442-1454, 2016.

SUMMARY: Walter Thiel developed the method that enables preservation of the body with natural colors in 1992. It consists in the application of an intravascular injection formula, and maintaining the corps submerged for a determinate period of time in the immersion solution in the pool. After immersion, it is possible to maintain the corps in a hermetically sealed container, thus avoiding dehydration outside the pool. The aim of this work was to review the Thiel method, searching all scientific articles describing this technique from its development point of view, and application in anatomy and morphology teaching, as well as in clinical and surgical practice. Most of these studies were carried out in Europe. We used PubMed, Ebsco and Embase databases with the terms "Thiel cadaver", "Thiel embalming", "Thiel embalming method" and we searched for papers that cited Thiel's work. In comparison with methods commonly used with high concentrations of formaldehyde, this method lacks the emanation of noxious or irritating gases; gives the corps important passive joint mobility without stiffness; maintaining color, flexibility and tissue plasticity at a level equivalent to that of a living body. Furthermore, it allows vascular repletion at the capillary level. All this makes for great advantage over the formalinfixed and fresh material. Its multiple uses are applicable in anatomy teaching and research; teaching for undergraduates (prosection and dissection) and for training in surgical techniques for graduates and specialists (laparoscopies, arthroscopies, endoscopies).

KEY WORDS: Embalming; Dissection; Walter Thiel; Surgical training; Review.

\section{INTRODUCTION}

The aim to preserve the body has existed since ancient times. This wish was in response to questions of a religious nature and the need to allow the deceased the passage to eternal life. With the beginning of human body studies and although religious rites remained in place, the need arose to preserve cadavers for prolonged periods of time. Several centuries passed until the discovery of formaldehyde (18th century), which has been the fixative par excellence until today. However, its toxicity and its use which results in increased cadaver stiffness and tissue darkening makes dissection and the practice of surgical techniques on the cadaver difficult. Therefore, in addition to the need to preserve bodies with characteristics that approximate the fresh cadaver as much as possible, considerable research has been devoted to search for the right solution to reduce and/or substitute the use of formaldehyde.
Among these solutions is the one created in 1992 by anatomist Walter Thiel. His fixation method involves preserving the body with natural colors through intravascular injection of a solution and subsequent immersion in a second solution for a determined amount of time, allowing the cadaver to be stored in a sealed container, outside the tank, without preservation fluid. This method of handling the cadaver is more efficient and convenient, and lacks the toxic or irritating gases due to minimum formaldehyde concentrations used in the formula.

The Thiel embalming method uses, among other components, 4-chloro-3-methylphenol as well as various salts for fixation, boric acid for disinfection, and ethylene glycol for the preservation of tissue plasticity (Thiel, 1992; 2002) (Table I).

\footnotetext{
* Plastination and Anatomical Techniques Laboratory, Research Center in Dental Sciences (CICO), Dental School, Universidad de La Frontera, Temuco, Chile.

** Doctoral Program in Morphological Sciences, School of Medicine, Universidad de La Frontera, Temuco Chile.

**** Department of Physical Education, School of Education, Universidad de La Frontera, Temuco, Chile.

***** Center of Biomedical Research, Universidad Autónoma de Chile, Chile.
} 
Table I. Basic composition of injection and immersion solutions described by W. Thiel in 1992 .

Solution A
Boric acid $3 \mathrm{~g}$
Ethylene glycol $30 \mathrm{ml}$
Ammonium nitrate $20 \mathrm{~g}$
Potassium nitrate $5 \mathrm{~g}$
Hot water $100 \mathrm{ml}$
Solution $\boldsymbol{B}$
Ethylene glycol $10 \mathrm{ml}$
4-chloro-3-methylphenol $1 \mathrm{ml}$

Injection Solution Solution A $14300 \mathrm{ml}$ Formaldehyde $300 \mathrm{ml}$ Sodium sulfate $700 \mathrm{~g}$ Solution B $500 \mathrm{ml}$

\author{
Immersion Solution \\ Ethylene glycol $10 \mathrm{ml}$ \\ Formaldehyde $2 \mathrm{ml}$ \\ Solution B $2 \mathrm{ml}$ \\ Boric acid $3 \mathrm{~g}$ \\ Ammonium nitrate $10 \mathrm{~g}$ \\ Potas sium nitrate $10 \mathrm{~g}$ \\ Sodium sulfate $7 \mathrm{~g}$ \\ Hot water $100 \mathrm{ml}$
}

The cadavers are perfused via the femoral or carotid artery with an intravascular solution containing $14300 \mathrm{~mL}$ of solution A, plus $500 \mathrm{~mL}$ of solution B and the addition of $700 \mathrm{~g}$ of sodium sulfite as well as $300 \mathrm{~mL}$ formalin (Table I) for a body weighing $80 \mathrm{~kg}$.

The original study described perfusion of the lungs with additional solutions using a tracheal tube, the intestine using a gastric tube and the brain through the superior sagittal sinus. These procedures seem to be unnecessary in cadavers used for surgical training courses (Balta et al., 2015a). Cadavers are stored for approximately 6 months in the immersion solution that contains $3 \%$ (w/v) boric acid, $10 \%$ (v/v) (mono-) ethylene glycol, $10 \%$ $(\mathrm{v} / \mathrm{v})$ ammonium nitrate, $5 \%(\mathrm{w} / \mathrm{v})$ potassium nitrate, $7 \%(\mathrm{w} / \mathrm{v})$ sodium sulfite, $2 \%(\mathrm{v} / \mathrm{v})$ formalin and $2 \%(\mathrm{v} / \mathrm{v})$ of solution B. After that, the cadavers are kept in zipper polyethylene bags. The cadavers can be used for months or years (Thiel, 1992, 2002; Balta et al., 2015b). The formalin content of the fixative is drastically reduced, with a final concentration of $0.8 \%$ of the total formula, and thus the odor is reduced (Balta et al., 2015b).

The result of the application of the Thiel formula is a non-irritating and almost odorless product, preserving the color, flexibility and plasticity very similar to the living body with ample joint mobility that maintains tissue elasticity, apt for training surgical techniques and invasive clinical procedures.

The aim of this work was to review the Thiel embalming method, identifying authors who developed the original technique, those who modified it, and the studies showing the various uses of the body embalmed with this method in relation to teaching anatomy, morphology, and development of clinical and surgical abilities and skills. New anesthetic techniques, imaging and so forth are also examined, noting advantages and drawbacks in the application of this method compared to other fixation and preservation techniques.

\section{METHODOLOGY}

A review of the Thiel method was realized, searching in "Pubmed", "Ebsco", "Embase" where the following terms were used: "Thiel embalming," "Thiel embalming method", "Thiel cadaver" also searching all articles that have cited Thiel's work. This search, conducted between March 21 and April 4, 2016, yielded 79 articles (Table II), and we added one article not included in these databases.

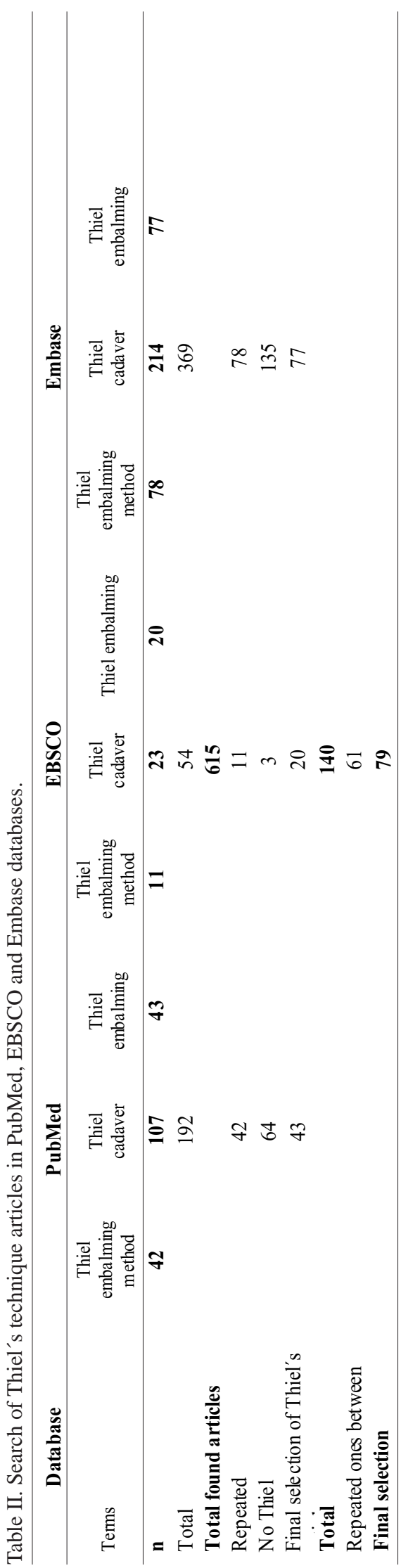


The search for scientific articles related to the development of Thiel's technique and its countless applications was carried out using PubMed, EBSCO and Embase databases. Applying the terms "Thiel embalming," "Thiel embalming method" and "Thiel cadaver" 192, 54 and 371 articles from each database were found for a total of 617 articles. From this last number, repeated articles and those that did not correspond to Thiel's technique were identified and eliminated and thus it was reduced to 43 PubMed articles, 20 EBSCO articles and 79 Embase articles. A total of 142 articles were gathered. Finally, we compared these 142 articles and those that repeated were removed, reaching the final number of 81 articles (Table II).

In the search carried out of databases mentioned, and after selecting a total of 82 articles related to the Thiel embalming method, these were classified according to subject matter: anesthesia 10 articles, anatomic dissection 10 articles, method explanation 6 articles, animal models 4 articles, education 5 articles, surgical techniques (plastic, laparoscopic, gastric band surgery) 22 , anatomic techniques 8 , imaging 8 , biomechanics 4 , original article by Thiel 2, study of the middle ear 1 .

\section{DESCRIPTION OF THE THIEL METHOD AND ITS VARIANTS}

In 2011 a survey was conducted in 311 anatomy centers worldwide, which established that only $11 \%$ of centers regularly use the Thiel embalming method, and all were European. It confirmed further, that formalin was still the most frequently used fixative for embalming (Benkhadra et al., 2011a).

In South America, the Thiel method has been developed in Argentina, by the Dissection Team of the Anatomy Chair, at the Faculty of Medicine at the Universidad de Buenos Aires (Bertone et al., 2011).

As described initially (Table I), the Thiel method is basically comprised of two types of solutions: intravascular injection and immersion. In this regard, since the appearance of the Thiel method in 1992, many authors have reproduced the original technique (Groscurth et al., 2001; Wolff etal., 2008; Hölzle et al., 2012; Hunter et al., 2014; Cabello et al., 2015; Willaert et al., 2016) and in more recent studies, they have made modifications to the technique: in compound concentrations, in their combination and in the creation of solutions (Kerckaert et al., 2008; Bertone et al.; Eisma et al., 2013b; Hayashi et al., 2014; Hammer et al., 2015a) (Tables III and IV). The cadavers are perfused using the internal saphenous vein (Thiel, 1992; Groscurth et al.) and in case of difficulty finding it, the femoral or the common carotid artery can be used (Bertone et al.; Hammer et al., 2015a).

Thiel also describes another series of solutions to inject into the body: intrathecal, intratracheal and intrarectal (Thiel, 1992, 2002; Groscurth; Wolff et al., 2008; Hunter et al.; Cabello et al.). Nevertheless, not many authors have used them (Bertone et al.; Hammer et al., 2015a). Thiel (1992) indicates that every solution has to be prepared and used immediately, but this is not necessary with the main solution (solution A).

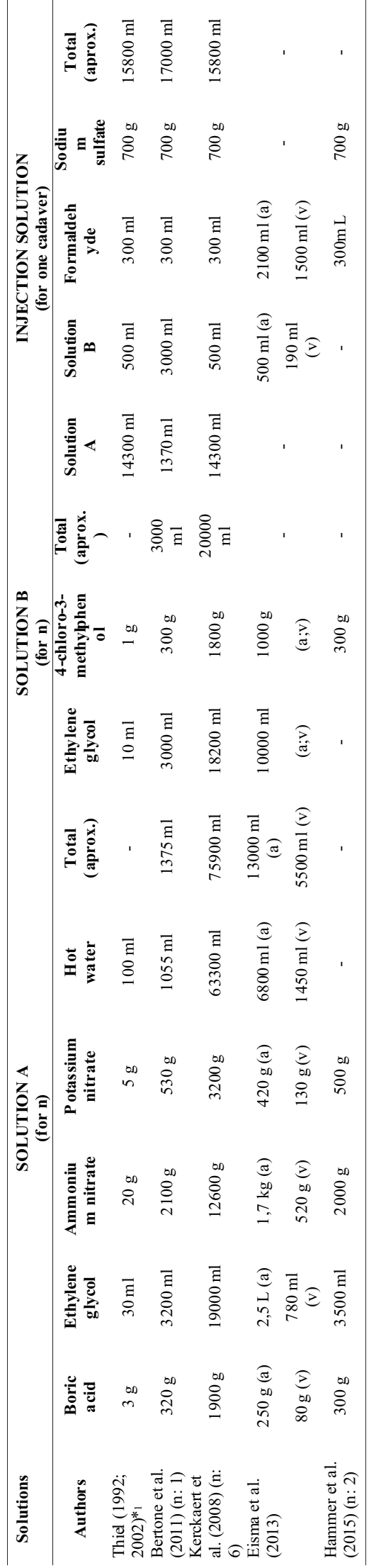


With respect to variations of Thiel's technique, some authors explained the reason to apply these modifications. Hammer et al. (2015a), modified the injection site, injecting the femoral artery instead of the external iliac artery, saving work time in the cadaver. Eisma et al. (2013b), use lower formalin concentrations as opposed to the standard formalin concentration ( $8.9 \%$ vs $37.5 \%)$, reducing the solution toxicity.

Another variation reported was the time the cadaver was kept in the immersion solution. In Thiel's original technique (1992), the immersion time is six months. However, Bertone et al. kept the body submerged for one month; Hammer et al. (2015a) and Eisma et al. (2013b) for two months; Healy et al. (2015) for two to three months; and Kerckaert et al. described the immersion of cadavers between four and six weeks.

None of the authors, who adapt the Thiel's original solutions, compared the results with Thiel's original technique.

Despite variations in the application of Thiel's original method (Kerckaert et al.; Bertone et al.; Eisma et al., 2013b; Hayashi et al., 2014; Hammer et al., 2015a) the results in terms of the characteristics of the cadavers were similar in all studies; the cadavers were well maintained and had good color preservation.

The advantages of the Thiel method over embalming with formaldehyde were found to be, limited exposure to pathogens, less use of inhalable toxic products, a significant reduction in formaldehyde use. In relation to tissues, the color and texture were similar to the living body, maintaining the integrity of the three vessel layers (Odobescu et al., 2014). In terms of joint mobility, the Thiel-embalmed cadaver presented joint flexibility and muscle elasticity (Hayashi et al., 2014; Bertone et al.). Compared to fresh cadavers, although they also allow joint mobility to be studied efficiently with real coloration and minimal modifications to the tissue forms, the time of use is reduced, with rapid deterioration and advancement of the decaying process in a few hours, with the ensuing high risk of infections in the individuals handling these cadavers (Hayashi et al., 2016; Bertone et al.).

Moreover, Thiel-embalmed cadavers can be injected with various types of dyes, resins, natural latex, among others, that enable even the smallest vascular branches (smaller than $1 \mathrm{~mm}$ ) to be identified, with the opportunity to visualize the entire vascularization (Hubmer et al., 2004; Bertone et al.; Healey et al., 2015).

The Thiel-embalmed cadavers are preserved for more than a year after removal from the embalming tank (Healey et al., 2015). Bertone et al. managed a correct preservation of the cadaver for three years with regular administration of the immersion fluid for hydration, just as Eisma et al. (2013a) who also reported the various surgical techniques to which cadavers were subject during the training of specialists. After the three years mentioned, the cadavers were disposed of by cremation. By contrast, Balta et al. (2015a) carried out a historical review and comparison of embalming techniques, suggesting that further research is needed on the chemical secreted prior to cremation of the Thiel-embalmed cadavers. Janczyk et al. (2011), mention that some chemicals used in the Thiel method are toxic and highly flammable, explosive and extremely dangerous for health and the environment.

The Thiel soft-fix embalming method for preserving cadavers with "natural colors" achieves well preserved organs and tissues, with natural color, consistency, flexibility, plasticity and transparency based on three processes: fixation, disinfection (bactericide) and preservation with solutions that contain 4-chloro-3-methywhich phenol acting as a fixative, boric acid which acts as disinfectant and ethylene glycol for the preservation of tissue plasticity, as the basic components (Thiel, 1992; Groscurth et al.; Thiel, 2002; Kerckaert et al.; Wolff et al., 2008; Bertone et al.; 
Hölzle et al.; Eisma et al., 2013b; Hayashi et al., 2014; Hammer et al., 2015a; Healey et al., 2015; Hunter et al.; Cabello et al.; Willaert et al., 2016). Sodium sulfate and formalin are added just prior to perfusion. The final formaldehyde concentration is less than $0.8 \%$. Formaldehyde contributes antiseptic properties (Hammer et al., 2015a). The salts used (ammonium nitrate, potassium nitrate, sodium sulfate) absorb the water in the tissues, the nitrates they contain give the muscles a more reddish color through the action of the nitrosomyoglobin that is formed from the muscles themselves (Janczyk et al.; Hammer et al., 2015a). Thiel (1992) established that ethylene glycol is responsible for the haptic properties of the tissues. It is a fact that the preservation odor with this method is faint; it is also effective in disinfection and does not release noxious substances into the environment (Verstraete et al., 2015). Thiel confirmed the disinfection efficacy of the technique by bacteriologic tests and none of the cadavers showed mold (Thiel 1992). Kerckaert et al., cited the same.

Thiel $(1992,2002)$ described a special solution for brain fixation: tap water $40 \mathrm{~mL}$, (mono) ethylene glycol $10 \mathrm{~mL}$, Isopropyl alcohol $40 \mathrm{~mL}$ and Formalin $10 \mathrm{~mL}$. The application of this solution is done with a lumbar puncture needle trough the lamina cribosa of the ethmoid bone, to get to the subarachnoid space in direction to the Bregma to get the anterior horn of the lateral ventricle and finally to get to the corpus callosum cistern. With this procedure, the solution will reach brain and spinal cord. Thiel described that a peristaltic pump may be used for this perfusion that allows a constant flow of the fixation solution $(0,17-19 \mathrm{~mL} / \mathrm{min})$. The softness of the brain conservation was fixed by the addition of high concentrations of formalin.

Kerckaert et al. said that in future studies they will apply Thiel's techniques for fixation of the central nervous system.

Eljamel et al. (2014) did some imaging studies of Thiel embalmed cadavers with MRI, revealing a good imaging with clear differentiation of white and gray matters, that suggested that it was a very good preservation of the brain.

Benkadra et al. (2011a) and Bertone et al. obtained a bad brain preservation with Thiel's method. Probably, because they did not use Thiel's specific brain solution.

To prove what Thiel said about the good flexibility and plasticity preservation in organs and tissues, several authors studied the biomechanical properties. Liao et al. (2015) studied the elastic properties of the ankle tendons and ligaments to evaluate the deformation rates. The results of this study of biomechanical traction demonstrated that the elasticity of Thiel-embalmed tendons and ligaments increases with the rate of deformation.
Verstraete et al. analyzed the elastic modulus, concluding that Young's modulus of human tissue is significantly altered in Thiel-embalmed tendons, a key determinant for the biomechanical properties, observing an increase in stiffness compared to fresh frozen samples.

Referencing studies by Liao et al. and Verstraete et al., Hammer et al. (2015b) wrote a letter to the editor mentioning that, to allow a more detailed interpretation of the results, it would be useful to know how material slippage and the stiffness of the testing machine were determined. They also established the need to add a summary of the Thiel fixative composition, in view of the existence of some variations, recommending that greater care be taken when determining that "Thiel-embalmed tissues are sufficiently similar to fresh tissues and suitable for many procedures and applications" (Liao et al.) on the basis of three donors, since, as they say very well, "Many other factors influence the final effect of Thiel embalming" (Verstraete et al.).

For their part, Joy et al. (2015) made a comparative quantitative evaluation with Young's modulus of the properties of Thiel-preserved tissues using shear wave elastography. The result was that the elasticity of the different tissues was similar in Thiel soft-embalmed cadavers and living humans. The elasticity was predicted by the embalming time and the tissue type, but not by the age at death or gender. In addition, there was a decrease in the mechanical efficiency of the bone after six months of immersion in the Thiel solution (Unger et al., 2010).

Another study researched the effects of Thiel embalming on the deep flexor tendons of fingers on cadavers versus fresh frozen cadavers and with rat tail tendon fascicles, because this is a well-established biomechanical model of a tendon. However, the results showed differences in the tendons preserved with the Thiel method in collagen fiber networks, likely due to the partial denaturation caused by boric acid. The tendons of Thiel-embalmed cadavers do not realistically represent the biomechanical characteristics of fresh frozen tendons (Fessel et al., 2011). Wilke et al. (2011) compared the biomechanical properties of the spine between fresh and Thiel-embalmed calf cadavers, concluding that the Thiel fixation maintains the non-linear load deformation but increases the range of motion. Therefore, they prefer fresh spinal columns for quantitative biomechanical testing since these maintain physiological conditions. Nevertheless, for preliminary orientation tests, the use of Thiel-preserved cadavers is recommended.

In other studies, preserved cadaver heads using the Thiel method have been used to analyze the mechanics of the middle ear in humans, with bone conduction, for clinical 
Table V. Hayashi et al. (2014) (n: 2)

\begin{tabular}{|c|c|c|c|c|c|c|}
\hline \multicolumn{2}{|c|}{ SOLUTION A } & \multicolumn{2}{|c|}{ SOLUTION B } & \multicolumn{3}{|c|}{ SOLUTION C } \\
\hline $\begin{array}{l}\text { 4-chloro-3- } \\
\text { methylphenol }\end{array}$ & Ethylene glycol & Ammonium nitrate & Hot water & $\begin{array}{l}\text { Boric } \\
\text { acid }\end{array}$ & $\begin{array}{l}\text { Potassium } \\
\text { nitrate }\end{array}$ & Hot water \\
\hline $66 \mathrm{~g}$ & $660 \mathrm{ml}$ & $2500 \mathrm{~g}$ & $4000 \mathrm{ml}$ & $370 \mathrm{~g}$ & $620 \mathrm{~g}$ & $5000 \mathrm{ml}$ \\
\hline \multicolumn{7}{|c|}{ RESERVE SOLUTION } \\
\hline Solution A & Solution B & Solution C & Propylene glycol & Hot water & & \\
\hline $660 \mathrm{ml}$ & $4000 \mathrm{ml}$ & $5000 \mathrm{ml}$ & $3700 \mathrm{ml}$ & $3300 \mathrm{ml}$ & & \\
\hline \multicolumn{7}{|c|}{ FINAL SOLUTION } \\
\hline Reserve solution & Sodium sulfate & $20 \%$ Formaldehyde & Morpholine & Ethanol & Total & \\
\hline $16660 \mathrm{ml}$ & $800 \mathrm{~g}$ & $600 \mathrm{ml}$ & $300 \mathrm{ml}$ & $1300 \mathrm{ml}$ & $18860 \mathrm{ml}$ & \\
\hline
\end{tabular}

use in diagnosis and for the manufacture of headsets. Thiel embalming has the advantage of durability, which makes it possible to conduct experiments for long periods of time with reproducible results (Guignard et al., 2013).

In reference to disinfection ability, Thiel (1992) described that for cadaver conservation, the possibility of infection of conserved material must be considered. That is why he determined the bacteriological effects of conservation solutions through qualitative experiments from suspension culture, according to DGHM (Deutsche Gesellschaft für Hygiene und Mikrobiologie) standards to prove and assess the disinfectant effect of formula components. The utilized bacteria were: Staphylococcus aureus, Pseudomonas aeruginosa and Mycobacterium tuberculosum. Thiel's conservation solutions were compared to a solution of phenol $5 \%$ and a solution of formalin 5\%. Notably, the infusion solution of the cadavers 1989 and viscera solution 1989 did not show major differences. On the other hand, phenol solution $5 \%$ on Pseudomona effect, was very similar to viscera solution 1989, and did not differ either with infusion solution 1989. All germs were eliminated after five minutes of being diluted at $75 \%$. With formalin solution, results with or without serum were much worse. In its non-diluted state it required 60 minutes to eliminate Staphylococcus and Mycobacterium and when diluted at $50 \%$ it took 6 hours. Nevertheless, viscera solution diluted at $50 \%$ killed all bacteria after 5 minutes. Even with immersion solution 1986, which is not as strong, the results were far better in its non-diluted state than with formalin solution at $5 \%$. This clearly shows that Thiel's conservation solutions have strong disinfection powers, however it would be incorrect to state that cadavers remain germ-free after long periods of conservation. Mugrowsky (1935, cited by Thiel, 1992), was able to demonstrate that after conserving cadavers in formalin and phenol, numerous aerobic and anaerobic bacteria survived.

It was determined that bacterial infections in dissection rooms did not have importance, but doubts remain whether AIDS can be excluded from these conclusions. In regards to this topic, at Graz University where the composition and effect of both new and old conservation solutions were studied, they noted in 1988: "According to experimental and practical information, these measures are enough to safely kill the HIV".

Since it was considered sufficient to stop the bacteria increase to prevent the bacterial decomposition effect in the cadaver, blood cultures in Staphylococcus and Pseudomonas under the inactivation substance CSL $+3 \%$ Tween $80+3 \%$ Saponin $+0,1 \%$ Cystein $+0,1 \%$ Histidin were made. For cadaver infusion dissolution diluted at 7.5 $\%$ in Staphylococcus an increase was not detected. Neither was an increase detected in 3 out of 4 samples of Pseudomonas. The viscera dissolution 1989 did not show either Pseudomonas or Staphylococcus increase (Thiel, 1992).

The blood culture with "phenol" dissolution at $5 \%$ showed similar results, while the results with formalin dissolution at $5 \%$ show effects on both bacteria, down to a dissolution of $2.5 \%$. This shows that formalin dissolution at $5 \%$ has better inhibition results in comparison with phenol dissolution at $5 \%$ but with worse disinfection results (Thiel, 1992).

Normally, in this injection procedure, conservation liquid equivalent to $1 / 4$ of the cadaver's weight is added; considering that it is distributed evenly, a concentration of $20 \%$ of conservation liquid should be detected. Just $1 / 3$ of this concentration is enough to stop the bacteria increase, so after the injection solution, the cadaver should be safe from bacterial decomposition effects (Thiel, 1992).

The immersion solution without diluting it has a high safety factor to obtain a great cadaver conservation. With the immersion solution diluted at $90 \%$ Staphylococcus aureus is killed in 10 minutes, Pseudomonas aeruginosa is eliminated in 5 minutes and Mycobacterium tuberculosum in 15 minutes (Thiel, 1992). 
The drawbacks of the Thiel method were primarily the high costs of the required materials and assembly. In addition, it did not allow identification of the thrombogenic potential in the practice of vascular sutures (Odobescu et al., 2014). The preparations had to be preserved in hermetically sealed bags between $0^{\circ}$ and $6^{\circ} \mathrm{C}$ to avoid mummification (Healey et al., 2015). Bertone et al. also kept the cadavers in hermetically sealed bags, but at room temperature $\left(20^{\circ} \mathrm{C}\right)$, although constantly controlling the dehydration of the body by regularly submerging it in the immersion tank. The appearance of blisters and blemishes can occur when exposed to the air for prolonged periods. Occasionally, due to causes unknown, the organs can display a gelatinous consistency (Benkhadra et al., 2011a).

Histological and morphological studies have been conducted comparing muscle fibers and tendons in fresh frozen cadavers embalmed with the Thiel method and with formalin, trying to identify anomalies in the tissue that explain the mobility of Thiel-embalmed cadavers. Staining was also used to visualize collagen and keratin. The collagen structure that forms the base of the muscle structure was preserved. The muscle fibers appeared as if they had been cut or ground, but were contained in a collagen sheath that stays intact, thereby preserving the general shape of the muscle. It is considered that boric acid is responsible for the damage observed (Benkhadra et al., 2011b). There is also less preservation of the histological characteristics, which would make using these cadavers for this type of research difficult (Hayashi et al., 2016).

Various articles described Thiel's method applications. Thiel-embalmed cadavers have been used to carry out morphometric studies of anatomical muscle variations (Pichler et al., 2005; 2007), insertions (Grechenig et al., 2000), perforating vessels (Kappler et al., 2005), that have clinical implications in reconstructive surgery, repairs and reinforcement of tendons, and prophylaxis. Thanks to the Thiel technique, vessel diameters are very well preserved (Anderhuber, 2005). Anatomical studies have been conducted to implement new, standardized, non-invasive techniques to find certain anatomical structures in order to reduce the rate of injury or paralysis during osteosynthesis surgery (Lim et al., 2012). Hubmer et al. carried out dissection work and an analysis of the use of the term "recurrent" in the recurrent branch of the posterior interosseous artery of the distal part of the forearm.

Some anatomy centers have indicated that the cadavers are not suitable for dissections lasting several hours. Bertone et al., however, stated that when cadavers are well hydrated with the immersion solution, they can be subjected to daily sessions of at least 5 hours of dissection without difficulties.

The lumbar sympathetic trunk has been investigated for the identification of anatomical reference points through topographical studies correlated with images to locate its block point (Grechenig et al.). In addition, the posterior branch of the spinal nerve has been studied in relation to epidural anesthesia procedure (Saito et al., 2006). Feigl et al. (2011; 2013a) studied spondylopathies, their influence on the retroperitoneal spaces in the lumbar sympathetic trunk and their impact on the distribution of local anesthesia.

Several authors have determined the minimum volume of anesthetic product for application in three procedures: local anesthesia during breast surgery (Guay \& Grabs, 2011), ultrasound-guided application (Desroches et al., 2013), and the stellate ganglion block (Feigl et al., 2007a).

Studies have been done on a supraomohyoid plexus block to avoid complications or collateral effects on other nerves (Feigl et al., 2006) and the spread of local anesthetic to block peripheral nerves (Munirama et al., 2012). For their part, Feigl et al. (2013b), identified a simple orientation mark to carry out the vertical obturator nerve block. In 2014, Feigl et al., evaluated the anatomical distribution of the nerves and its relation to the lumbar plexus to avoid the occurrence of interference complications during the block. Benkhadra et al. (2012), explained the possible failures during the ultrasound-guided infraclavicular nerve block. In addition, comparative studies have been done between Thieldembalmed and fresh cadavers for training in the new ultrasound-guided anesthetic technique in the cervical region (Benkhadra et al., 2009).

De Crop et al. (2012), studied the correlation between the physical and clinical image of the thorax x-ray in Thielembalmed cadavers using insufflation of the lungs while the image was being taken to simulate the pulmonary anatomy view on the thorax $\mathrm{x}$-ray.

Sikora et al. (2015) used samples of the anterior wall of the vagina from patients who had had a hysterectomy, which were preserved in one of four ways: i) in cold, ii) fresh without fixation, iii) with formaldehyde, and iv) with Thiel solution, to demonstrate the potential of multiphoton microscopy in the study and 3D analysis of the extracellular matrix of the pelvic organs, in which they detected collagen and elastin, for later comparison with standard histological methods. The authors found no differences in collagen and elastin volumes when comparing the samples from the four groups. 
Karakitsios et al. (2014a; 2014b) conducted studies to estimate the value of proton resonance frequency (PRF), as a preclinical model, for treatment with MRguided focused ultrasound in human and bovine liver and porcine muscle. The PRF coefficient values measured in the Thiel-embalmed tissue were higher than for the fresh tissue; these results can be explained by the chemical composition of Thiel's fluid and electrical conductivity. Another study reported that the PRF in the focused ultrasound machine must be calibrated in order to apply it in Thiel-embalmed tissues. Gueorguieva et al. (2014) identified signal and contrast loss in clinical MRI sequence images due to high conductivity of fluids from the Thiel method.

Using elastography, changes in the muscle module section with, and without the tissues that cover it (skin and epimysium) were examined. The short muscle module decreased significantly by $50 \%$ after the skin was eliminated (Yoshitake et al., 2016). Ando et al. (2014) analyzed the validity of estimating fascicle length in the vastus lateralis and intermedius of the quadriceps by ecography, concluding that quality of echographic images of Thiel-embalmed cadavers is equivalent to the quality of images obtained from living human beings.

Eljamel et al. (2014) suggest that long-term use of these cadavers (up to 15 months) makes the Thiel embalmed cadaver an excellent model for any other computer-assisted image-guided, minimally-invasive neurosurgery for training, such as DBS insertion. They consider that Thiel embalmed cadavers can be used for developing and testing various stereotactic functional neurosurgical procedures

Kerckaert et al. reported the results of the creation of the Endogent center, a center for anatomy and invasive techniques at the University of Ghent, Belgium, publishing their work experiences and uses of the Thiel embalming technique. The group that founded the center received specialist training at the University of Fribourg, Switzerland to learn this technique, which maintains the flexibility, plasticity and color of the cadavers and organs like a living person, with movable joints, the only difference being the absence of blood flow. They used the Thiel method for its subsequent use in education and surgical specialization courses for medical professionals in various techniques and procedures.

Expert anesthetists executed ventilation maneuvers with mask and tracheal intubation by direct laryngoscopy using Thiel-embalmed cadavers and mannequins, concluding that the Thiel-embalmed cadavers were more suitable for the ventilation with mask and provided a more realistic atmosphere for the laryngoscopy and tracheal intubation than the mannequins (Szucs et al., 2016). In addition, they have been used as a training method for regional anesthesia, as they present almost ideal conditions for the practice of this procedure (Feigl et al., 2007a; 2007b).

Results were published of a survey administered to undergraduate and graduate anatomy students on the experience of working with Thiel- and formalin-embalmed cadavers (Balta et al., 2015a). In the results students found that the Thiel solution was less irritating than formalin, raising concerns about the preservation of the nervous system and the difference in appearance of Thiel-embalmed cadavers and the images in the texts. Thus, the authors proposed that new books and manuals on dissection be produced. They demonstrated that surgical training has been successful in almost all areas using Thiel-embalmed cadavers. The appearance similar to the living body increases the risk of emotional and psychological impact on students after their first dissection session. It is possible to avoid this by preparing the students before their first encounter with Thielembalmed cadavers. According to Bertone et al., at no time has this been proven beyond the normal reaction of certain students in front of a cadaver, a situation that also occurred with formalin-embalmed cadavers.

One article presented the courses given at the University of Switzerland for the management of the new Thiel soft-fix embalming technique and construction of models that can be used for training in the microsurgery of paranasal sinuses, rhinoplasty and facial plastic surgery, surgery of the temporal bone (Groscurth et al.; Feigl et al., 2008), neurosurgery of the middle and posterior cranial fossa, endoscopic surgery of the abdomen and pelvis, interventional neuroradiology, and other techniques. Through these changes, knowledge of the macroscopic anatomy is improved as an essential topic for surgical training in this specialization (Groscurth et al.). An analysis of the usefulness of cadavers in anatomy education takes into account the importance of cadavers, considered "silent teachers", as they teach things that books or 3D software cannot, such as the anatomical variability between individuals, the effect of diseases or lifestyle on the body and the different textures and behavior of tissues (Eisma \& Wilkinson, 2014).

The use of conventional embalming techniques with formalin presents an important limitation in terms of tissue texture (stiffer), odor, durability, as well as the impossibility of creating the pneumoperitoneum in formalin-embalmed cadavers, and thus the difficulty of undertaking endoscopic surgical techniques (Healey et al., 2015; Feigl et al., 2013b; Liao et al.). In this review, a large amount of literature was found that proposes the use of the Thiel-embalmed cadaver as a simulator to replicate surgical techniques and the training of surgeons. This is due to the preservation of real 
characteristics and the easy manipulation that such cadavers present (Bertone et al.; Eisma \& Wilkinson; Healey et al., 2015). This way, the use of Thiel-embalmed cadavers has extended to various areas of surgery, particularly urological surgery (Healey et al., 2015), thyroidectomies (Eisma et al., 2011), cricothyroidotomies (Benkhadra et al., 2008), liver surgery simulations (Eisma et al., 2013a), arthroplasty (Windisch et al., 2001; Kamei et al., 2013), artery sutures (Odobescu et al., 2014; 2015), peripheral nerve repair (Matzi et al., 2015), flap surgeries (Hassan et al., 2014a; Wolff et al., 2014), neurosurgery (Schwalenberg et al., 2010), anastomosis techniques (Hassan et al., 2014b) and their comparison with animal models. Skills development in the area of angiology and laparoscopy are an additional advantage, several studies indicating the possibility of producing a pneumoperitoneum in the patient with the aim of accurately recreating abdominal laparoscopic surgery (Giger et al., 2008; Slieker et al., 2012) at kidney level (Prasad Rai et al., 2012; Ubee et al., 2014; Rai et al., 2015). Thus, it has been proven that the preservation of anatomical characteristics in Thiel-embalmed cadavers is adequate and allows for the realistic recreation of surgery.

Studies with Thiel-embalmed cadaver faces were conducted for cosmetic purposes, determining that the filling of the premaxillary space is an opportunity to make discrete corrections of the philtrum, in addition to having a better filling for superficial injections (Pilsl et al., 2014). Okada et al. (2012) reported using Thiel-embalmed cadavers for preoperative assessments and confirmed their usefulness, especially for the prevention of complications, or in the evaluation of surgical approaches. They concluded that Thielembalmed cadavers have many advantages over cadavers preserved with other methods and that they would also be useful for the development of new surgical implements or for the evaluation of a surgeon's abilities.

Holzle et al. (2012) used Thiel's technique to preserve cadavers destined for education and training courses in oral surgery and implantology through the positioning of dental implants in cadavers. This is the only study that applied Thiel's solution for such surgical training. The differences with respect to the animal models lie in certain differences in the morphology of the bone and teeth compared to the human, and the absence of resistance in the virtual models when performing the procedure. The advantages of animal and virtual models, on the other hand, lie in their reusability, which is not the case with a human cadaver.

Thiel's technique has also been applied to animals, mainly to produce animal models for the training of various surgical techniques. Willaert et al. (2014) created an animal model to achieve reperfusion of the porcine pulmonary vascular system using an injector pump, by means of which they introduced paraffin perliquidum into the pig's vascular system. They were able to determine that the paraffin perliquidum was suitable to reproduce reperfusion of the porcine pulmonary vascular system; however, found that the small vessels were broken in the process. In another study, Willaert et al. (2015) developed a model similar to the previous one to reproduce renal circulation. Later, Willaert et al. (2016) also produced another animal model for porcine vascular reperfusion that adequately reproduced the blood flow, reaching the vessels of the small intestine, providing real coloration of the serosa and mucosa as well as the remaining organs, achieving a more realistic reperfusion of the kidney with preservation of the anatomy. These researchers used methylene blue to identify the scope of the artificially produced reperfusion, and were able to prove that Thiel's technique is a low-viscosity solution, that passes easily through the capillary walls. Similarly, among some of the limitations raised by this study was the accumulation of the incorporated liquid, making it difficult to visualize the anatomical structures and their reperfusion.

Hassan et al. (2015) made a comparative study of surgical simulations for the repair of zone II flexor tendons in Thiel-embalmed human and porcine cadavers. They also compared them to formalin-embalmed cadavers. They showed the benefits of Thiel-embalmed cadavers in terms of better tissue flexibility, which allowed a correct surgical repair of the tendon, preserving the anatomy compared to formalin-embalmed cadavers and porcine models, with the latter being the most frequently used in surgical technique classes due to their greater availability. Thus, the superior usefulness of Thiel-embalmed cadavers for surgical practice was demonstrated.

\section{CONCLUSIONS}

Walter Thiel's method of fixation and preservation of cadavers with "natural colors" is based on three processes: fixation, disinfection, preservation with solutions that contain 4-chloro-3-methylphenol, potassium nitrate, ammonium nitrate, sodium sulfite, boric acid and monoethylene glycol as basic components. Thiel's original and complete technique is complex in both its preparation and application in cadavers, nevertheless, this technique enables a prolonged preservation, maintaining the color, texture, plasticity and flexibility, similar to a fresh specimen. While using this method, storage does not require the use of tanks except for rehydration. In addition, it allows the injection of vessels and canaliculi up to the thinnest branches. 
All these characteristics that Thiel-embalmed cadavers present, make possible their use with great advantage over formalin-embalmed cadavers, and even over fresh material due to the simplicity of their handling, reduced toxicity and prolonged duration. Their multiple uses are applicable in morphological research for the purpose of undergraduate and graduate teaching, in addition to training in specialized surgical techniques.

When analyzing the literature, the advantage of working directly on a human body is noteworthy, exceeding the possibilities of doing so on animal or vir- tual models which, though they aid in developing skills, do not have the same value of incorporating knowledge, as has the practice on a real human model.

Walter Thiel's technique of preserving the body in natural colors is a valuable contribution to the field of cadaver preservation and a breakthrough in the elimination of formaldehyde as the only fixative and preservative method, presenting a number of advantages that render it the first choice, when implementing a technique that is useful in education as well as research and surgical training.

OTTONE, N. E.; VARGAS, C. A.; FUENTES, R. \& DEL SOL, M. Método de embalsamamiento de Walther Thiel. Revisión de las soluciones y sus aplicaciones en diferentes campos de investigación biomédica. Int. J. Morphol., 34(4):1442-1454, 2016.

RESUMEN: En 1992, Walter Thiel desarrolló el método que permite la preservación del cuerpo con colores naturales. Consiste en la aplicación de una fórmula de inyección intravascular y el mantenimiento del cuerpo sumergido en pileta, en una solución de inmersión específica, durante un período determinado de tiempo. Después de la inmersión, es posible mantener el cuerpo en un recipiente herméticamente sellado, evitando así la pérdida del líquido fijador, fuera de la pileta. El objetivo de este trabajo fue revisar el método de Thiel, buscando todos los artículos científicos que describen esta técnica desde el punto de vista de su desarrollo, y su aplicación en la enseñanza de la anatomía y morfología, así como en la práctica clínica y quirúrgica. La mayoría de estos estudios se realizaron en Europa. Utilizamos las bases de datos PubMed, Ebsco y Embase con los términos "Thiel cadaver", "Thiel embalsamamiento", "método de embalsamamiento de Thiel" y se buscaron los documentos que citan el trabajo de Thiel. En comparación con los métodos comúnmente utilizados con altas concentraciones de formaldehído, este método carece de emanación de gases nocivos o irritantes; Da al cuerpo una movilidad articular pasiva importante sin rigidez; Manteniendo el color, la flexibilidad y la plasticidad del tejido a un nivel equivalente al de un cuerpo vivo. Además, permite la repleción vascular a nivel capilar. Todo esto hace una gran ventaja sobre el material fijado con formalina y fresco. Sus usos múltiples son aplicables en la enseñanza y la investigación de la anatomía; (prosección y disección) y para la formación en técnicas quirúrgicas para graduados y especialistas (laparoscopias, artroscopias, endoscopias).

PALABRAS CLAVE: Embalsamamiento; Disección; Walter Thiel; Entrenamiento quirúrgico; Revisión.

\section{REFERENCES}

Anderhuber, F. Personal communication according (successor of W. Thiel). In: Kappler, U. A.; Constantinescu, M. A.; Büchler, U. \& Vögelin, E. Anatomy of the proximal cutaneous perforator vessels of the gracilis muscle. Br. J. Plast. Surg. 58(4):445-8, 2005 .

Ando, R.; Taniguchi, K.; Saito, A.; Fujimiya, M.; Katayose, M. \& Akima, H. Validity of fascicle length estimation in the vastus lateralis and vastus intermedius using ultrasonography. $J$. Electromyogr. Kinesiol., 24(2):214-20, 2014.

Balta, J. Y.; Cronin, M.; Cryan, J. F. \& O'Mahony, S. M. Human preservation techniques in anatomy: A 21st century medical education perspective. Clin. Anat., 28(6):725-34, 2015a.

Balta, J. Y.; Lamb, C. \& Soames, R. W. A pilot study comparing the use of Thiel- and formalin-embalmed cadavers in the teaching of human anatomy. Anat. Sci. Educ., 8(1):86-91, 2015 b.

Benkhadra, M.; Lenfant, F.; Nemetz, W.; Anderhuber, F.; Feigl, G. \& Fasel, J. A comparison of two emergency cricothyroidotomy kits in human cadavers. Anesth. Analg., 106(1):182-5, 2008.
Benkhadra, M.; Faust, A.; Ladoire, S.; Trost, O.; Trouilloud, P.; Girard, C.; Anderhuber, F. \& Feigl, G. Comparison of fresh and Thiel's embalmed cadavers according to the suitability for ultrasound-guided regional anesthesia of the cervical region. Surg. Radiol. Anat., 31(7):531-5, 2009.

Benkhadra, M.; Gérard, J.; Genelot, D.; Trouilloud, P.; Girard, C.; Anderhuber, F. \& Feigl, G. Is Thiel's embalming method widely known? A world survey about its use. Surg. Radiol. Anat., 33(4):359-63, 2011a.

Benkhadra, M.; Bouchot, A.; Gérard, J.; Genelot, D.; Trouilloud, P.; Martin, L.; Girard, C.; Danino, A.; Anderhuber, F. \& Feigl, G. Flexibility of Thiel's embalmed cadavers: the explanation is probably in the muscles. Surg. Radiol. Anat., 33(4):365-8, $2011 b$.

Benkhadra, M.; Faust, A.; Fournier, R.; Aho, L. S.; Girard, C. \& Feigl, G. Possible explanation for failures during infraclavicular block: an anatomical observation on Thiel's embalmed cadavers. Br. J. Anaesth., 109(1):128-9, 2012. 
Bertone, V. H.; Blasi, E.; Ottone, N. E. \& Dominguez, M. L. Walther Thiel method for the preservation of corpses with maintenance of the main physical properties of vivo. Rev. Argent. Anat. Online, 2(3):89-92, 2011.

Cabello, R.; González, C.; Quicios, C.; Bueno, G.; García, J. V.; Arribas, A. B. \& Clascá, F. An experimental model for training in renal transplantation surgery with human cadavers preserved using W. Thiel's embalming technique. J. Surg. Educ., 72(2):1927, 2015

De Crop, A.; Bacher, K.; Van Hoof, T.; Smeets, P. V.; Smet, B. S.; Vergauwen, M.; Kiendys, U.; Duyck, P.; Verstraete, K.; D'Herde, K. \& Thierens, H. Correlation of contrast-detail analysis and clinical image quality assessment in chest radiography with a human cadaver study. Radiology, 262(1):298-304, 2012.

Desroches, J.; Grabs, U. \& Grabs, D. Selective ultrasound guided pectoral nerve targeting in breast augmentation: How to spare the brachial plexus cords? Clin. Anat., 26(1):49-55, 2013.

Eisma, R.; Mahendran, S.; Majumdar, S.; Smith, D. \& Soames, R. W. A comparison of Thiel and formalin embalmed cadavers for thyroid surgery training. Surgeon, 9(3):142-6, 2011.

Eisma, R.; Gueorguieva, M.; Immel, E.; Toomey, R.; McLeod, G.; Soames, R. \& Melzer, A. Liver displacement during ventilation in Thiel embalmed human cadavers - a possible model for research and training in minimally invasive therapies. Minim. Invasive Ther. Allied Technol., 22(5):291-6, 2013a.

Eisma, R.; Lamb, C. \& Soames, R. W. From formalin to Thiel embalming: What changes? One anatomy department's experiences. Clin. Anat., 26(5):564-71, 2013b.

Eisma, R. \& Wilkinson, T. From "silent teachers" to models. PLoS Biol., 12(10):e1001971, 2014.

Eljamel, S.; Volovick, A.; Saliev, T.; Eisma, R. \& Melzer, A. Evaluation of Thiel cadaveric model for MRI-guided stereotactic procedures in neurosurgery. Surg. Neurol. Int., 5(Suppl. 8):S4049, 2014.

Feigl, G.; Fuchs, A.; Gries, M.; Hogan, Q. H.; Weninger, B. \& Rosmarin, W. A supraomohyoidal plexus block designed to avoid complications. Surg. Radiol. Anat., 28(4):403-8, 2006.

Feigl, G.; Anderhuber, F.; Schwarz, G.; Dorn, C.; Fasel, J. \& Likar, R. Training methods for regional anaesthesia. Evaluation and comparison. Anaesthesist, 56(5):437-43, 2007a.

Feigl, G. C.; Rosmarin, W.; Stelzl, A.; Weninger, B. \& Likar, R. Comparison of different injectate volumes for stellate ganglion block: an anatomic and radiologic study. Reg. Anesth. Pain Med., 32(3):203-8, $2007 \mathrm{~b}$.

Feigl, G.; Kos, I.; Anderhuber, F.; Guyot, J. P. \& Fasel, J. Development of surgical skill with singular neurectomy using human cadaveric temporal bones. Ann. Anat., 190(4):316-23, 2008.
Feigl, G. C.; Kastner, M.; Ulz, H.; Breschan, C.; Dreu, M. \& Likar, $\mathrm{R}$. Topography of the lumbar sympathetic trunk in normal lumbar spines and spines with spondylophytes. Br. J. Anaesth., 106(2):260-5, 2011.

Feigl, G. C.; Kastner, M.; Ulz, H.; Breschan, C.; Pixner, T., Dreu, M.; Umschaden, H. W. \& Likar, R. The lumbar sympathetic trunk: its visibility and distance to two anatomical landmarks. Surg. Radiol. Anat., 35(2):99-106, $2013 \mathrm{a}$.

Feigl, G. C.; Ulz, H.; Pixner, T.; Dolcet, C.; Likar, R. \& SandnerKiesling, A. Anatomical investigation of a new vertical obturator nerve block technique. Ann. Anat., 195(1):82-7, 2013 b.

Feigl, G. C.; Dreu, M.; Ulz, H.; Breschan, C.; Maier, C. \& Likar, R. Susceptibility of the genitofemoral and lateral femoral cutaneous nerves to complications from lumbar sympathetic blocks: is there a morphological reason? Br. J. Anaesth., 112(6):1098-104, 2014.

Fessel, G.; Frey, K.; Schweizer, A.; Calcagni, M.; Ullrich, O. \& Snedeker, J. G. Suitability of Thiel embalmed tendons for biomechanical investigation. Ann. Anat., 193(3):237-41, 2011.

Giger, U.; Frésard, I.; Häfliger, A.; Bergmann, M. \& Krähenbühl, L. Laparoscopic training on Thiel human cadavers: a model to teach advanced laparoscopic procedures. Surg. Endosc., 22(4):9016, 2008

Grechenig, W.; Clement, H.; Egner, S.; Tesch, N. P.; Weiglein, A. \& Peicha, G. Musculo-tendinous junction of the flexor carpi ulnaris muscle. An anatomical study. Surg. Radiol. Anat., 22(5-6):25560, 2000.

Groscurth, P.; Eggli, P.; Kapfhammer, J.; Rager, G.; Hornung, J. P. \& Fasel, J. D. Gross anatomy in the surgical curriculum in Switzerland: improved cadaver preservation, anatomical models, and course development. Anat. Rec., 265(6):254-6, 2001.

Guay, J. \& Grabs, D. A cadaver study to determine the minimum volume of methylene blue or black naphthol required to completely color the nerves relevant for anesthesia during breast surgery. Clin. Anat., 24(2):202-8, 2011.

Gueorguieva, M. J.; Yeo, D. T.; Eisma, R. \& Melzer, A. MRI of Thiel-embalmed human cadavers. J. Magn. Reson. Imaging, 39(3):576-83, 2014.

Guignard, J.; Stieger, C.; Kompis, M.; Caversaccio, M. \& Arnold, A. Bone conduction in Thiel-embalmed cadaver heads. Hear Res., 306:115-22, 2013.

Hammer, N.; Löffler, S.; Bechmann, I.; Steinke, H.; Hädrich, C. \& Feja, C. Comparison of modified Thiel embalming and ethanolglycerin fixation in an anatomy environment: Potentials and limitations of two complementary techniques. Anat. Sci. Educ., $8(1): 74-85,2015$ a.

Hammer, N.; Schröder, C. \& Schleifenbaum, S. On the suitability of Thiel-fixed samples for biomechanical purposes: Critical considerations on the articles of Liao et al. "Elastic Properties 
of Thiel-Embalmed Human Ankle Tendon and Ligament" and Verstraete et al. "Impact of Drying and Thiel Embalming on Mechanical Properties of Achilles Tendons". Clin. Anat. doi: 10.1002/ca.22679, 2015b.

Hassan, S.; Eisma, R.; Soames, R.; Waterston, S. \& Harry, L. Raising of microvascular flaps using the Thiel cadaveric model. J. Plast. Reconstr. Aesthet. Surg., 67(4):e107-8, 2014a.

Hassan, S.; Eisma, R. \& Harry, L. E. Surgical training of anastomotic technique using Thiel cadavers. J. Plast. Reconstr. Aesthet. Surg., 67(10):e250-1, 2014b.

Hassan, S.; Eisma, R.; Malhas, A.; Soames, R. \& Harry, L. Surgical simulation flexor tendon repair using Thiel cadavers: a comparison with formalin embalmed cadavers and porcine models. J. Hand Surg. Eur. Vol., 40(3):246-9, 2015.

Hayashi, S.; Homma, H.; Naito, M.; Oda, J.; Nishiyama, T.; Kawamoto, A.; Kawata, S.; Sato, N.; Fukuhara, T.; Taguchi, H.; Mashiko, K.; Azuhata, T.; Ito, M.; Kawai, K.; Suzuki, T.; Nishizawa, Y.; Araki, J.; Matsuno, N.; Shirai, T.; Qu, N.; Hatayama, N.; Hirai, S.; Fukui, H.; Ohseto, K.; Yukioka, T. \& Itoh, M. Saturated salt solution method: a useful cadaver embalming for surgical skills training. Medicine (Baltimore), 93(27):e196, 2014.

Hayashi, S.; Naito, M.; Kawata, S.; Qu, N.; Hatayama, N.; Hirai, S. \& Itoh, M. History and future of human cadaver preservation for surgical training: from formalin to saturated salt solution method. Anat. Sci. Int., 91(1):1-7, 2016.

Healy, S. E.; Rai, B. P.; Biyani, C. S.; Eisma, R.; Soames, R. W. \& Nabi, G. Thiel embalming method for cadaver preservation: a review of new training model for urologic skills training. Urology, 85(3):499-504, 2015

Hölzle, F.; Franz, E. P.; Lehmbrock, J.; Weihe, S.; Teistra, C.; Deppe, H. \& Wolff, K. D. Thiel embalming technique: a valuable method for teaching oral surgery and implantology. Clin. Implant Dent. Relat. Res., 14(1):121-6, 2012.

Hubmer, M. G.; Fasching, T.; Haas, F.; Koch, H.; Schwarzl, F.; Weiglein, A. \& Scharnagl, E. The posterior interosseous artery in the distal part of the forearm. Is the term "recurrent branch of the anterior interosseous artery" justified? Br. J. Plast. Surg., 57(7):638-44, 2004.

Hunter, A.; Eisma, R. \& Lamb, C. Thiel embalming fluid--a new way to revive formalin-fixed cadaveric specimens. Clin. Anat., 27(6):853-5, 2014.

Janczyk, P.; Weigner, J.; Luebke-Becker, A.; Kaessmeyer, S. \& Plendl, J. Nitrite pickling salt as an alternative to formaldehyde for embalming in veterinary anatomy--A study based on histo- and microbiological analyses. Ann. Anat., 193(1):71-5, 2011.

Joy, J.; McLeod, G.; Lee, N.; Munirama, S.; Corner, G.; Eisma, R. \& Cochran, S. Quantitative assessment of Thiel soft-embalmed human cadavers using shear wave elastography. Ann. Anat., 202:52-6, 2015.
Kamei, G.; Ochi, M.; Okuhara, A.; Fujimiya, M.; Deie, M.; Adachi, N.; Nakamae, A.; Nakasa, T.; Ohkawa, S.; Takazawa, K.; Eguchi, A.; Katou, T.; Takada, T. \& Usman, M. A. A new distraction arthroplasty device using magnetic force; a cadaveric study. Clin. Biomech. (Bristol, Avon), 28(4):423-8, 2013.

Kappler, U. A.; Constantinescu, M. A.; Büchler, U. \& Vögelin, E. Anatomy of the proximal cutaneous perforator vessels of the gracilis muscle. Br. J. Plast. Surg., 58(4):445-8, 2005.

Karakitsios, I.; Dogadkin, O.; Le, N. \& Melzer, A. Measurement of proton resonance frequency shift coefficient during MR-guided focused ultrasound on Thiel embalmed tissue. Magn. Reson. Med. doi: 10.1002/mrm.25378, 2014a.

Karakitsios, I.; Bobeica, M.; Saliev, T.; Rube, M. \& Melzer, A. Thermometry during MR-guided focused ultrasound in a preclinical model based on Thiel embalmed tissue. Minim. Invasive Ther. Allied Technol., 23(2):120-6, 2014b.

Kerckaert, I.; Van Hoof, T.; Pattyn, P. \& D’Herde, K. Endogent: Centre for Anatomy and Invasive Techniques. Int. J. Exp. Clin. Anat., 2:28-33, 2008.

Liao, X.; Kemp, S.; Corner, G.; Eisma, R. \& Huang, Z. Elastic properties of Thiel-embalmed human ankle tendon and ligament. Clin. Anat., 28(7):917-24, 2015.

Lim, R.; Tay, S. C. \& Yam, A. Radial nerve injury during double plating of a displaced intercondylar fracture. J. Hand Surg. Am., 37(4):66972, 2012.

Matzi, V.; Hörlesberger, N.; Hohenberger, G. M.; Rosenlechner, D.; Dolcet, C.; Weiglein, A. H.; Maier, M. J. \& Grechenig, S. Minimally invasive approach to the radial nerve--A new technique. Injury, 46(12):2374-8, 2015.

Munirama, S.; Satapathy, A. R.; Schwab, A.; Eisma, R.; Corner, G. A.; Cochran, S.; Soames, R. \& McLeod, G. A. Translation of sonoelastography from Thiel cadaver to patients for peripheral nerve blocks. Anaesthesia, 67(7):721-8, 2012.

Odobescu, A.; Moubayed, S. P.; Daniels, E. \& Danino, M. A. Horizontal mattress technique for anastomosis of size-mismatched vessels. Plast. Surg. (Oakv.), 23(2):100-2, 2015.

Odobescu, A.; Moubayed, S. P.; Harris, P. G.; Bou-Merhi, J.; Daniels, E. \& Danino, M. A. A new microsurgical research model using Thiel-embalmed arteries and comparison of two suture techniques. J. Plast. Reconstr. Aesthet. Surg., 67(3):389-95, 2014.

Okada, R.; Tsunoda, A.; Momiyama, N.; Kishine, N.; Kitamura, K.; Kishimoto, S. \& Akita, K. Thiel's method of embalming and its usefulness in surgical assessments. Nihon Jibiinkoka Gakkai Kaiho, 115(8):791-4, 2012.

Pichler, W.; Tesch, N. P.; Grechenig, W.; Tanzer, K. \& Grasslober, M. Anatomical variations of the flexor hallucis longus muscle and the consequences for tendon transfer. A cadaver study. Surg. Radiol. Anat., 27(3):227-31, 2005. 
Pichler, W.; Tesch, N. P.; Grechenig, W.; Leithgoeb, O. \& Windisch, G. Anatomic variations of the musculotendinous junction of the soleus muscle and its clinical implications. Clin. Anat., 20(4):444-7, 2007.

Pilsl, U.; Rosmarin, W. \& Anderhuber, F. The premaxillary space: a location for filler injection? Dermatol. Surg., 40(3):301-4, 2014.

Prasad Rai, B.; Tang, B.; Eisma, R.; Soames, R. W.; Wen, H. \& Nabi, G. A qualitative assessment of human cadavers embalmed by Thiel's method used in laparoscopic training for renal resection. Anat. Sci. Educ., 5(3):182-6, 2012.

Rai, B. P.; Stolzenburg, J. U.; Healy, S.; Tang, B.; Jones, P.; Sweeney, C.; Somani, B. K.; Biyani, C. S. \& Nabi, G. Preliminary validation of Thiel embalmed cadavers for laparoscopic radical nephrectomy. J. Endourol., 29(5):595603, 2015.

Saito, T.; Yoshimoto, M.; Yamamoto, Y.; Miyaki, T.; Itoh, M.; Shimizu, S.; Oi, Y.; Schmidt, W. \& Steinke, H. The medial branch of the lateral branch of the posterior ramus of the spinal nerve. Surg. Radiol. Anat., 28(3):228-34, 2006.

Schwalenberg, T.; Neuhaus, J.; Liatsikos, E.; Winkler, M.; Löffler, S. \& Stolzenburg, J. U. Neuroanatomy of the male pelvis in respect to radical prostatectomy including three-dimensional visualization. B. J. U. Int., 105(1):21-7, 2010.

Sikora, M.; Scheiner, D.; Betschart, C.; Perucchini, D.; Mateos, J. M.; di Natale, A.; Fink, D. \& Maake, C. Label-free, three-dimensional multiphoton microscopy of the connective tissue in the anterior vaginal wall. Int. Urogynecol. J., 26(5):685-91, 2015.

Slieker, J. C.; Theeuwes, H. P.; van Rooijen, G. L.; Lange, J. F. \& Kleinrensink, G. J. Training in laparoscopic colorectal surgery: a new educational model using specially embalmed human anatomical specimen. Surg. Endosc., 26(8):2189-94, 2012.

Szucs, Z.; László, C. J.; Baksa, G.; László, I.; Varga, M.; Szuák, A.; Nemeskéri, Á. \& Tassonyi, E. Suitability of a preserved human cadaver model for the simulation of facemask ventilation, direct laryngoscopy and tracheal intubation: a laboratory investigation. Br. J. Anaesth., 116(3):417-22, 2016.

Thiel, W. Die Konservierung ganzer Leichen in natürlichen Farben. Ann. Anat., 174:185-95, 1992.

Thiel, W. Ergànzung für die Konservierung ganzer Leichen nach W. Thiel. Ann. Anat., 184:267-9, 2002.

Ubee, S. S.; Tang, B.; Eisma, R.; Biyani, C. \& Nabi, G. Laparoscopic renal resection training in cadavers embalmed using Thiel's method: Development and evaluation of skills learning. Eur. Urol. Suppl., 13:e875, 2014.

Unger, S.; Blauth, M. \& Schmoelz, W. Effects of three different preservation methods on the mechanical properties of human and bovine cortical bone. Bone, 47(6):1048-53, 2010.
Verstraete, M. A.; Van Der Straeten, C.; De Lepeleere, B.; Opsomer, G. J.; Van Hoof, T. \& Victor, J. Impact of drying and thiel embalming on mechanical properties of achilles tendons. Clin. Anat., 28(8):994-1001, 2015.

Wilke H. J, Werner K, Häussler K, Reinehr M \& Böckers, T. M. Thiel-fixation preserves the non-linear load-deformation characteristic of spinal motion segments, but increases their flexibility. J. Mech. Behav. Biomed. Mater, 4(8):2133-7, 2011.

Willaert, W.; Van Hoof, T.; De Somer, F.; Grabherr, S.; D'Herde, K.; Ceelen, W. \& Pattyn, P. Postmortem pump-driven reperfusion of the vascular system of porcine lungs: towards a new model for surgical training. Eur. Surg. Res., 52(1-2):8-20, 2014.

Willaert, W.; De Vos, M.; Van Hoof, T.; Delrue, L.; Pattyn, P. \& D'Herde, K. Understanding Thiel embalming in pig kidneys to develop a new circulation model. PLoS One, 10(3):e0120114, 2015.

Willaert, W.; Tozzi, F.; Van Hoof, T.; Ceelen, W.; Pattyn, P. \& D"Herde, K. Lifelike Vascular Reperfusion of a Thiel-Embalmed Pig Model and Evaluation as a Surgical Training Tool. Eur. Surg. Res., 56(3-4):97-108, 2016.

Windisch, G.; Grechenig, W.; Peicha, G.; Tesch, N. P. \& Seibert, F. J. Capsular attachment to the distal radius for extracapsular placement of pins. Surg. Radiol. Anat., 23(5):313-6, 2001.

Wolff, K. D.; Kesting, M.; Mücke, T.; Rau, A. \& Hõlzle, F. Thiel embalming technique: a valuable method for microvascular exercise and teaching of flap raising. Microsurgery, 28(4):2738, 2008.

Wolff, K. D.; Fichter, A.; Braun, C.; Bauer, F. \& Humbs, M. Flap raising on pulsatile perfused cadaveric tissue: a novel method for surgical teaching and exercise. J. Craniomaxillofac. Surg., 42(7):1423-7, 2014.

Yoshitake, Y.; Miyamoto, N.; Taniguchi, K.; Katayose, M. \& Kanehisa, H. The Skin Acts to Maintain Muscle Shear Modulus. Ultrasound Med. Biol., 42(3):674-82, 2016.

\section{Correspondence to: \\ Nicolas Ernesto Ottone \\ Plastination Laboratory \\ Faculty of Dentistry \\ Universidad de La Frontera \\ Av. Francisco Salazar 01145 \\ Temuco \\ CHILE}

E-mail: nicolas.ottone@ufrontera.cl

Received: 16-08-2016

Accepted: 22-09-2016 